\title{
HSV-1 and Alzheimer's disease: more than a hypothesis
}

\section{Roberto Piacentini ${ }^{1}$, Giovanna De Chiara ${ }^{2}$, Domenica D. Li Puma ${ }^{1}$, Cristian Ripoli ${ }^{1}$, Maria E. Marcocci ${ }^{3}$, Enrico Garaci ${ }^{4}$, Anna T. Palamara ${ }^{5,6}$ and Claudio Grassi ${ }^{1}$ *}

${ }^{1}$ Institute of Human Physiology, Medical School, Università Cattolica del Sacro Cuore, Rome, Italy

2 Institute of Translational Pharmacology, National Research Council, Rome, Italy

${ }^{3}$ Department of Public Health and Infectious Diseases, Sapienza University of Rome, Rome, Italy

${ }^{4}$ San Raffaele Pisana Scientific Institute for Research, Hospitalization and Health Care, Telematic University, Rome, Italy

${ }^{5}$ Department of Public Health and Infectious Diseases, Institute Pasteur Cenci Bolognetti Foundation, Sapienza University of Rome, Rome, Italy

${ }^{6}$ San Raffaele Pisana Scientific Institute for Research, Hospitalization and Health Care, Rome, Italy

\section{Edited by:}

Cesare Mancuso, Catholic University

School of Medicine, Italy

\section{Reviewed by:}

Ottavio Arancio, Columbia University, USA

Roberto Manservigi, University of Ferrara, Italy

\section{*Correspondence:}

Claudio Grassi, Institute of Human Physiology, Medical School, Università

Cattolica del Sacro Cuore, Largo

Francesco Vito 1, 00168 Rome, Italy

e-mail: grassi@rm.unicatt.it
Among the multiple factors concurring to Alzheimer's disease (AD) pathogenesis, greater attention should be devoted to the role played by infectious agents. Growing epidemiological and experimental evidence suggests that recurrent herpes simplex virus type-1 (HSV-1) infection is a risk factor for AD although the underlying molecular and functional mechanisms have not been fully elucidated yet. Here, we review literature suggesting the involvement of HSV-1 infection in AD also briefly mentioning possible pharmacological implications of these findings.

\section{Keywords: HSV-1, Alzheimer's disease, recurrent infection, $\gamma$ secretase, amyloid $-\beta$ protein}

\section{ALZHEIMER'S DISEASE, APP PROCESSING AND AMYLOID- $\beta$ PRODUCTION/ACCUMULATION}

Alzheimer's disease $(\mathrm{AD})$ is a neurodegenerative disorder characterized by progressive decline in cognitive functions leading to memory loss and dementia. It involves degeneration of limbic and cortical brain structures, especially in the temporal lobe. In 2010, it was estimated that 35.5 million individuals were affected by dementia in the world with a prediction that this number will increase to 65.7 million by 2030 , and 115.4 million by 2050 . The World Alzheimer Report 2010 (AD International) estimated that the total costs of dementia in 2010 were US\$ 604 billions. Most (>90\%) AD cases are sporadic. Only a minority of them have a genetic inheritance and are referred to as familial AD. The main risk factor for $\mathrm{AD}$ is aging. The disease afflicts $10 \%$ of the population over the age of 65 and $50 \%$ of the population over the age of 85 . Several factors may increase the chances to develop AD (Imtiaz et al., 2014). Among the "genetic" risk factors, the carriage of a type 4 allele of the apolipoprotein E gene (APOE- $\varepsilon 4$ ) has been widely recognized (see references in Kim et al., 2009). Among the "environmental" risk factors, persistent brain infections, particularly those induced by herpes simplex virus type-1 (HSV-1), seem to play a key role in $\mathrm{AD}$ pathogenesis. In a multifactorial disease like $\mathrm{AD}$, to identify the contribution made by each factor and the underlying mechanisms is critical to the development of new therapeutic strategies to prevent the disease and/or slow down its progression.

From the neuropathological point of view, the brains of $\mathrm{AD}$ sufferers are characterized by the presence of two major hallmarks mainly located in the hippocampus and cortex: extracellular amyloid plaques composed of insoluble aggregates of the amyloid- $\beta$ protein $(A \beta)$ and intraneuronal neurofibrillary tangles, composed of hyperphosphorylated Tau protein (Kosik et al., 1986). Numerous other conditions, among which oxidative stress (Mattson et al., 1993) and inflammation, due to microglia activation and astrocytosis, may concur to produce the structural and functional alterations typically found in $\mathrm{AD}$ brain (Kitazawa et al., 2004).

Amyloid- $\beta$ protein is a small protein (generally composed of 40 to 43 amino acids) generated by the proteolytic cleavage of the amyloid precursor protein (APP), a ubiquitous transmembrane protein whose functional role in cell biology has been only partially discovered. APP seems to be involved in neurite outgrowth and synaptogenesis, neuronal protein trafficking along the axon, transmembrane signal transduction, cell adhesion and $\mathrm{Ca}^{2+}$ signaling (Zheng and Koo, 2006; Octave et al., 2013). Among the various isoforms of APP, due to alternative splicing of $A P P$ gene located on chromosome 21 in humans, those of 695-amino acid length is prevalent in neurons whereas the other two forms, APP751 and APP770, are expressed in other tissues (Zhang et al., 2011).

Amyloid precursor protein is normally subjected to processing by specific enzymes called "secretases" (Nunan and Small, 2000). It may be processed along two different pathways. The first one, that is most frequent and "non amyloidogenic", involves sequential proteolytic cleavages by the $\alpha$ - and $\gamma$-secretases. The former cuts APP at a position 83 amino acids from the $\mathrm{C}$-terminus, thus producing a large $\mathrm{N}$-terminal domain $(\mathrm{sAPP} \alpha)$, normally secreted into the extracellular medium, whose function is not well defined. On the opposite site, the other 83-amino-acid C-terminal fragment (C83) is retained in the membrane and it is subsequently cleaved by the $\gamma$-secretase complex (that consists of presenilins, nicastrin, anterior pharynx-defective 1 and presenilin enhancer 2), producing a 
short fragment that is generally considered non-toxic and known as "p3". The amyloidogenic pathway begins when APP undergoes cleavage by the $\beta$-secretase, also known as $\beta$-site APP cleaving enzyme 1 or BACE-1 (Vassar et al., 1999). $\beta$-secretase cuts APP 16 amino acids before $\alpha$-secretase and yields two species, the large $\mathrm{N}$-terminal ectodomain of the precursor and the 99-amino acid Cterminus stub (C99). Subsequent cleavage of the latter fragment by $\gamma$-secretase results in the formation of $\mathrm{A} \beta$ species containing 40 to 42 amino acids. This also means that APP cleavage by $\alpha$-secretase prevents the $A \beta$ formation. On the other C-terminal side of APP, $\gamma$-secretase (in both amyloidogenic and non-amyloidogenic pathways) also generate the "APP intracellular domain" (AICD), that has been reported to modulate the transcription of several genes (including APP itself, BACE- 1 and the A $\beta$-degrading enzyme neprilysin), to regulate apoptosis and contribute to $\mathrm{AD}$ pathogenesis (Octave et al., 2013). In APP, the amino acid threonine in position 668 (Thr668) is an important site for its processing. Indeed, APP phosphorylation at Thr668 resulted in increased A $\beta$ formation (Lee et al., 2003; Pierrot et al., 2006). This amino acid is on the C-terminal region of APP and its phosphorylation also regulates the activity of AICD. In fact, when AICD is phosphorylated at Thr668 it interacts with the Fe65 adapter protein (Bórquez and González-Billault, 2012) and enters the nucleus, where it may regulate gene transcription and induce neurodegeneration (Chang et al., 2006).

Amyloidogenic cleavage of APP is not confined to cell membrane; it also takes place in several cellular compartments (Vetrivel and Thinakaran, 2006), including the intermediate compartment of the endoplasmic reticulum (Cook et al., 1997), the trans-Golgi network (Choy et al., 2012), and the endosomal/lysosomal system, where APP processing is regulated by cytoplasmic phosphorylation at Thr668 (Lee et al., 2003). For these reasons, A $\beta$ species may be secreted directly into the extracellular space, where their subsequent aggregation promotes senile plaque formation. Alternatively, it may remain within the cell or may be re-internalized in neurons, where it accumulates (Mohamed and Posse de Chaves, 2011). Some recent findings suggest that $A \beta$ accumulating in neurons, particularly in the form of small oligomers (especially dimers and trimers) is the major determinant of the synaptic damage that highly correlates with the cognitive deficits characterizing the early phases of the disease preceding neuronal death (Tampellini et al., 2007; Mucke and Selkoe, 2012; Ripoli et al., 2013). However, $A \beta$ is not a mere toxic peptide. It is constitutively produced and secreted by cells and, especially when present at very low concentration (in the range of $\mathrm{pM}$ ), it even supports synapses by increasing synaptic strength in the hippocampus (Puzzo et al., 2008, 2011).

In addition to secretases, APP may be processed by caspases (in particular caspase-3), especially in cells undergoing apoptosis (Gervais et al., 1999; Pellegrini et al., 1999; Fiorelli et al., 2013). In neurons, caspase-induced processing of APP generates a C-terminal fragment (C31) with neurotoxic potential (Lu et al., 2003; Nguyen et al., 2008). Moreover, Fiorelli et al. (2013) showed that caspases cleavage generates two APP fragments (APP-Fs) of $25-35 \mathrm{kDa}$ that are recognized by anti-A $\beta$ antibodies.

Among the genetic risk factors for $\mathrm{AD}$, the carriage of $A P O E$ $\varepsilon 4$ allele plays a major role. Apolipoproteins carry lipids in the circulation and regulate lipid metabolism. ApoE, expressed predominantly in astrocytes, is suggested to be involved in redistribution of cholesterol and phospholipids during membrane remodeling (Holtzman et al., 2012). Links between AD and APOE$\varepsilon 4$ are multiple: ApoE protein exists in 4 isoforms (E1 to E4), with ApoE3 being the most common allele, and it seems to play a role in $A \beta$ fibrillogenesis and oligomerization as well as in $A \beta$ clearance. Differently from the other three variants, ApoE4 exhibits scarce ability to bind $A \beta$, thus its expression contributes to $A \beta$ accumulation and aggregation inside neurons and influences the formation of the parenchymal amyloid plaques (Holtzman et al., 2012; Verghese et al., 2013). When human ApoE isoforms were expressed in APP transgenic mice, differences in extracellular A $\beta$ accumulation were observed in an isoform-dependent manner (E2 < E3 < E4; Holtzman et al., 2000). Similar results were also recently obtained by Hashimoto et al. (2012) who reported that the levels of $\mathrm{A} \beta$ oligomers in APOE $\varepsilon 4 / \varepsilon 4$ AD brains were 2.7 times higher than those found in APOE $\varepsilon 3 / \varepsilon 3$ AD brains, and that ApoE increased $A \beta$ oligomer levels in an isoform-dependent manner $(\mathrm{E} 2<\mathrm{E} 3<\mathrm{E} 4)$.

Finally, alterations of intracellular $\mathrm{Ca}^{2+}$ homeostasis and signaling have also been implicated in $\mathrm{AD}$ pathogenesis. It is well known that intracellular $\mathrm{Ca}^{2+}$, besides playing a pivotal role in a large number neuronal functions, is a critical determinant of neuronal survival and death (Piacentini et al., 2008a,b; Maiti et al., 2011; Bading, 2013). Several reports demonstrated correlation between $\mathrm{Ca}^{2+}$ homeostasis dysregulation leading to increased intracellular $\mathrm{Ca}^{2+}$ levels and AD (Green, 2009). Interestingly, ApoE expression in neuronal and glial cells correlates with increased intracellular $\mathrm{Ca}^{2+}$ concentrations in an isoform-dependent manner (E2 < E3 < E4; Müller et al., 1998).

\section{HOW CAN HSV-1 BE INVOLVED IN AD?}

Herpes simplex type 1 virus is a neurotropic double-stranded DNA virus that primarily infects epithelial cells of oral and nasal mucosa. Here virus undergoes lytic replication; the newly produced viral particles may enter sensory neurons and, by axonal transport, reach the trigeminal ganglion where usually establishes a latent infection. The virus undergoes periodic reactivation cycles in which the newly formed viral particles are transported back to the site of primary infection through the sensory neurons, causing the well-known clinical lesions (i.e., cold sores and blisters). However, the bipolar trigeminal ganglion neurons also project to the trigeminal nuclei located in the brainstem. From here, neurons project to the thalamus to finally reach the sensory cortex. This is the path through which the reactivated virus may reach the central nervous system (CNS), where it may cause acute neurological disorders like encephalitis [herpes simplex encephalitis (HSE)] or a mild, clinically asymptomatic, infection, or establish life-long latent infection (Kastrukoff et al., 1982; Lewandowski et al., 2002; references in Dobson et al., 2003). The weakening of immune system occurring during aging may favor this process. In addition to the neuronal route, HSV-1 may enter the CNS through the blood stream, as demonstrated by Burgos et al. (2002, 2003, 2005). Many experimental evidence, described below, suggest that accumulation of intracellular damage caused by repeated cycles of viral reactivation may concur to neurodegeneration. 
Some reports suggest that during infection herpes virus interacts with several human proteins that it uses to enter the cell and to move from plasma membrane to the nucleus and back (reviewed in Carter, 2008). HSV-1 also uses the host's transcriptional machinery to replicate and binds to proteins that control immune surveillance or apoptosis. Noteworthy, in the attempt to eliminate the virus, host may even cause cell damage via immune and inflammatory responses targeting the viruscontaining cells. If this happens in the CNS, HSV-1-induced inflammatory response may result in HSE or, in milder cases, in cell death and neurodegeneration.

Several epidemiological, immunological and molecular evidence link HSV-1 infections to AD pathogenesis. HSV-1 is a ubiquitous virus that affects more than $80 \%$ of people over 65 worldwide. The first evidence suggesting the involvement of HSV1 in $\mathrm{AD}$ dates back to 1982 and is based on the observation that people surviving to HSE showed clinical signs reminiscent of $\mathrm{AD}$ (i.e., memory loss and cognitive impairment), and that brain regions primarily affected in HSE (limbic system, frontal and temporal cortices) were the same regions compromised in $\mathrm{AD}$ (Ball, 1982). During the last 30 years several research groups have conducted many studies providing solid support to the involvement of HSV-1 infection in AD pathogenesis. Here we will briefly summarize the main results of these researches.

\section{EPIDEMIOLOGICAL DATA}

Several studies have been performed to assess the presence of HSV-1 in the brain of AD patients. After the first observations made by Ball (1982), other studies have demonstrated that HSE affected the same brain areas involved in $\mathrm{AD}$ in humans as well as in rodent experimental models (Damasio and Van Hoesen, 1985; Caparros-Lefebvre et al., 1996; Beffert etal., 1998; Wu etal., 2003; Taylor etal., 2007; Ando etal., 2008). Jamieson et al. (1992) and Itzhaki et al. (1997) reported that a high proportion (about 60\%) of brains of elderly people contained latent HSV-1 DNA, especially in the CNS regions critically involved in $\mathrm{AD}$. When present in AD brains, HSV-1 DNA was primarily located within amyloid plaques (Wozniak et al., 2009a). Whether or not the virus contributes to activation of pro-neurodegenerative pathways may largely depend on several host factors, including genetic predisposition, as described in greater detail below. Many infectious agents whose pathogenetic role has been established in other CNS diseases (e.g., varicella zoster virus, causing meningitis or encephalitis; Epstein-Barr virus, associated to both multiple sclerosis and CNS lymphoma; human herpes virus 6, associated to seizure in children) may infect subjects without producing evident clinical signs. On the other hand, even in the presence of "clinically silent" infection, virus may periodically reactivate and replicate in the CNS (Peter and Sevall, 2001; Bearer, 2012). There is no clear evidence on whether HSV-1 reaching the brain and infecting neurons resides there in latent form. However, the detection of HSV-1 DNA in the cerebro-spinal fluid (Deatly et al., 1988; Peter and Sevall, 2001; Plentz et al., 2008) suggests that HSV-1 replicates in the CNS (Bearer, 2012). The presence of HSV-1 proteins in hippocampal neurons of mice infected intraperitoneally with HSV-1 was demonstrated by Burgos et al. (2006a) who also showed that virus is reactivated by hyperthermia. After every reactivation, the newly produced viral particles generated by this "silent" replication and potentially reaching the brain might act, in a drop by drop fashion, to produce local brain damages that may largely differ from those of acute diseases like HSE. It has been recently reported that in brain of infected but asymptomatic mice, HSV-1 reactivation was associated to neuroinflammation and to the appearance of several markers of neurodegeneration including Tau hyperphosphorylation (Martin et al., 2013).

\section{IMMUNOLOGICAL DATA}

A number of studies have been conducted to demonstrate the association between $\mathrm{AD}$ and HSV-1 infection by searching for antibodies against HSV-1 in the blood of AD patients. These studies revealed a strong correlation between $\mathrm{AD}$ occurrence and HSV infection or reactivation, as addressed in a longitudinal study including 512 elderly persons looking for correlation between anti-HSV-1 IgM positivity (a marker of virus primary infection or its reactivation) and development of $\mathrm{AD}$-like cognitive dysfunctions (Letenneur et al., 2008). In the same study, no correlation was found between anti-HSV-1 IgG positivity and early dementia, thus suggesting that recurrent infection, rather the primary one, is dangerous for the CNS. Anti-HSV IgM levels, and not those of IgG, have also been found to inversely correlate with lower plasma $A \beta$ levels (Féart et al., 2011). It is believed that increased amyloid deposition in the brain is paralleled by a lowering of $A \beta$ levels in plasma and that low plasma $\mathrm{A} \beta$ levels might be considered possible short-term risk marker of dementia (Schupf et al., 2008; Lambert et al., 2009; Blennow et al., 2010). Another study recently demonstrated that HSV1 reactivation, assessed as anti-HSV IgG avidity index (that is a more accurate way to demonstrate viral reactivation) occurs in prodromal $\mathrm{AD}$ and highly correlates with symptoms of mild cognitive impairment (Kobayashi et al., 2013). Finally, Mancuso et al. (2014) recently found that elevated HSV-1 antibody titers were significantly more frequent in $\mathrm{AD}$ patients than in control healthy patients and that they positively correlated with cortical bilateral temporal and orbitofrontal gray matter volume, that may be considered an index of AD pathology (Whitwell et al., 2012).

\section{GENETIC DETERMINANTS}

Some studies have suggested that in people carrying the APOE- 4 allele and, therefore, predisposed to develop AD, HSV-1 infection markedly increases the risk of AD (Itzhaki et al., 1997; Itzhaki and Lin, 1998; references in Bearer, 2012). However, this correlation was not always confirmed (Beffert et al., 1998). APOE seems to affects the outcome of several different infections (Itzhaki et al., 1998; Dobson et al., 2003) and, interestingly, APOE- $\varepsilon 4$ is a risk factor for cold sores (Itzhaki and Wozniak, 2008). Some studies also demonstrated that ApoE4 presence influences the viral load in the brain. Indeed, viral spreading into the brain of ApoE KO mice was lower than that occurring in wild-type mice and correlation was reported between ApoE expression and HSV-1 DNA concentration detected in the CNS (Burgos et al., 2002). In a subsequent study, the same authors showed that during acute infection 
with HSV-1, ApoE4 was more efficient than ApoE3 in promoting viral colonization of the brain (Burgos et al., 2006b). However, many genes and proteins implicated in $\mathrm{AD}$, other than $\mathrm{ApoE}$, have been found to interact with herpes simplex viral genome or regulate its life cycle, further supporting the hypothesized synergy between host and pathogens in causing AD-like brain damage (Carter, 2008). From this point of view, genome wide association investigations (GWAs) carried out in a large cohort of $\mathrm{AD}$ and non-AD subjects also suggested an infective etiology for sporadic $\mathrm{AD}$. In particular, the polymorphism association of genes located on the chromosome 19 (i.e., Nectin-2 [NC-2]; APOE, glycoprotein carcinoembryonic antigen related cell adhesion molecule-16 [CEACAM-16]; B-cell lymphoma-3 [Bcl-3]; translocase of outer mitochondrial membrane 40 homolog [TOMM-40]) and on the chromosome 8 (complement receptor-1 [CR-1]; APOJ, C-type lectin domain A family-16 member [CLEC-16A]), results in a genetic fingerprint that might modulate brain susceptibility to herpes virus infection and lead to neuronal loss, inflammation and $\mathrm{A} \beta$ deposition (Porcellini et al., 2010; Licastro et al., 2011).

\section{MOLECULAR DATA}

Several studies demonstrated that HSV-1 affects APP processing. HSV-1 infection may have profound effects on the host intracellular pathways leading to activation/inactivation of several signaling molecules and kinases involved in APP metabolism. Ruth Itzhaki's group found that in human SH-SY5Y neuroblastoma cells HSV-1 induces APP cleavage with the production of a $55-\mathrm{kDa}$ fragment (recognized in Western blot analysis by an anti-C-terminal APP antibody) starting from $6 \mathrm{~h}$ post infection (hpi), and the concomitant reduction of band intensity relative to full-length APP (Shipley et al., 2005). These authors also reported that HSV-1 infection caused $A \beta 40$ and $A \beta 42$ accumulation in human neuroblastoma and glioblastoma cells in vitro, whereas in brains of mice infected with HSV-1 they only found an increase in A $\beta 42$ (Wozniak et al., 2007). However, further studies on in vivo models of recurrent HSV-1 brain infections are needed to determine the structural and functional alterations induced by viral reactivation.

We have demonstrated that in cultured neuronal cells HSV-1 induces amyloidogenic APP cleavage, with production of several APP-Fs including A $\beta$ (De Chiara et al., 2010; Piacentini et al., 2011). In particular, we found that infection of SH-SY5Y human neuroblastoma cells and rat cortical neurons with HSV-1 induces multiple cleavages of APP, which result in the intra- and/or extracellular accumulation of several APP-Fs with neurotoxic potential. Among them we found: (i) APP-Fs of 35 and $45 \mathrm{kDa}$ (APP-F35 and APP-F45) that comprise portions of A $\beta$; (ii) N-terminal APPFs that are secreted extracellularly; (iii) intracellular C-terminal APP-Fs, including AICD; and (iv) A $\beta 40$ and $A \beta 42$ in the form of monomers and small oligomers (dimers and trimers). Notably, the fragment APP-F35 seems to be a large A $\beta$ oligomer (probably a nonamer) that is typical of viral-induced APP processing given that it was only found in cells infected with HSV-1. Indeed, it was revealed with antibodies recognizing amino-acidic sequences in $\mathrm{A} \beta$ (e.g., $4 \mathrm{G} 8$ and $\mathrm{M} 2^{\circ}$, targeting amino acids 17-24 and 1-10 of $\mathrm{A} \beta$, respectively), only 8-18 hpi (Figures $\mathbf{1}$ and $2 \mathbf{A}$ ). Moreover, its formation was inhibited in the presence of $\beta$ - and $\gamma$-secretase inhibitors. APP-F45 was revealed by $\mathrm{M} 2^{\circ}$ only. On the contrary, neither of these APP-Fs were recognized by antibodies raised against the $\mathrm{N}$ - and C-terminals of APP (Figure 1), thus indicating that they are not APP cleavage end-products. We also demonstrated that APP-Fs were present in the extracellular space and they had the ability to induce apoptosis in the neighboring cells (De Chiara et al., 2010). The multiple cleavages of APP occurring in infected cells are produced in part by known components of the amyloidogenic APP processing pathway, i.e., host-cell $\beta$-secretase, $\gamma$-secretase, and caspase-3-like enzymes, and in part by other cellular or viral enzymes not yet identified. Incidentally, the increased production of $A \beta$ also reflected in an increased production and nuclear accumulation of AICD fragment that it is known to play a role in $\mathrm{AD}$ by modulating gene transcription.

It has been hypothesized that viral glycoprotein $\mathrm{B}$ is responsible for $A \beta$ aggregation because this glycoprotein shares a significant portion of amino acid sequence similarity with $A \beta$, and it might serve as "core" to trigger $A \beta$ aggregation (Cribbs et al., 2000). However, we and others (Wozniak et al., 2007; Piacentini et al., 2011) found that HSV-1-induced increased $A \beta$ immunoreactivity was not due to cross-reactivity of the anti-A $\beta$ antibodies with this glycoprotein.

From a functional point of view, we reported that HSV-1 binding to neuronal membrane induced membrane depolarization leading to increased neuronal excitability and triggering action potentials. This depolarization was due to activation of persistent $\mathrm{Na}^{+}$currents and inhibition of leak $\mathrm{K}^{+}$currents. Neuronal hyperexcitability persisted over time and was observed in neurons also at $12 \mathrm{hpi}$. Downstream to this effect we observed increased intracellular $\mathrm{Ca}^{2+}$ signaling, mainly due to activation of L-type $\mathrm{Ca}^{2+}$ channels and opening of inositol trisphosphate receptors $\left(\mathrm{InsP}_{3} \mathrm{Rs}\right)$ that caused marked intracellular $\mathrm{Ca}^{2+}$ entry from extracellular medium and $\mathrm{Ca}^{2+}$ release from intracellular stores (Piacentini et al., 2011). As above described, this $\mathrm{Ca}^{2+}$ dysregulation may trigger neurodegeneration (Mattson and Chan, 2003; Piacentini et al., 2008a,b; Chakroborty et al., 2012). We also found that HSV-1 induced $\mathrm{Ca}^{2+}$-mediated APP phosphorylation at Thr668. This is a key event critically involved in APP processing and $A \beta$ formation (Pierrot et al., 2006). We demonstrated that HSV-1 infection induces a significant accumulation of A $\beta 42$ inside neurons (Figure 2), and this effect depended on $\mathrm{Ca}^{2+}$ signaling activation. Indeed, in the presence of nifedipine and/or 2-aminoethoxydiphenyl borate (2-APB), that are specific blockers of L-type $\mathrm{Ca}^{2+}$ channels and $\mathrm{InsP}_{3}$ receptors, respectively, intraneuronal $A \beta$ accumulation was significantly reduced (Piacentini et al., 2011). Besides accumulating inside neurons, $A \beta$ monomers and small oligomers (dimers and trimers) were also released in the culture medium of infected neurons and revealed by Western blot analysis.

Several other studies have investigated the link between HSV1 and $\mathrm{AD}$ at molecular level, independently on APP processing. It has been demonstrated that HSV-1 infection causes several functional and molecular alterations including: neurodegeneration and $\mathrm{AD}$-like phosphorylation of tau protein (Zambrano et al., 2008; Wozniak et al., 2009b), the latter involving the activation of the glicogen sinthase kinase 3; caspase-3-mediated cleavage of Tau 

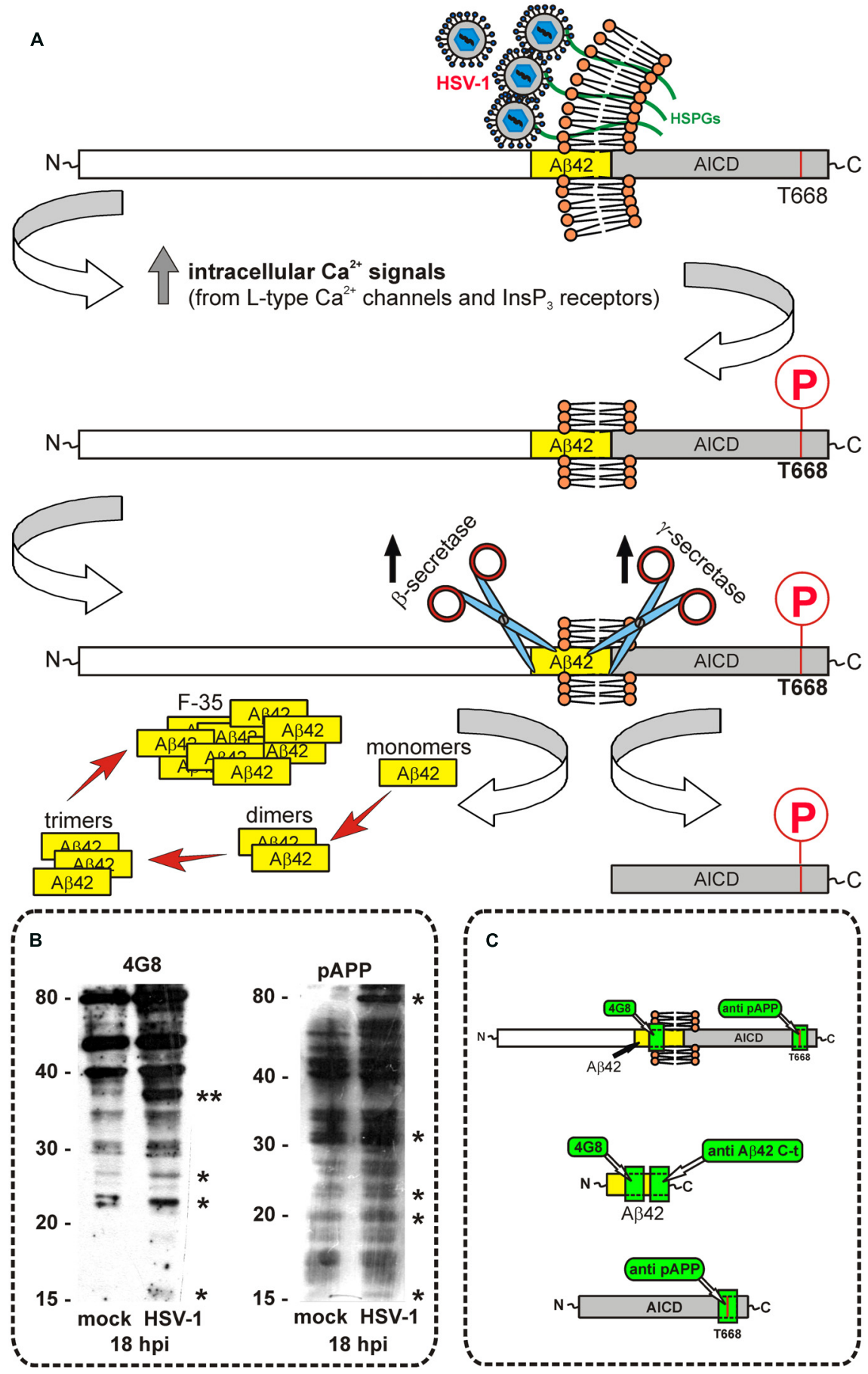

FIGURE 1 | HSV-1 infection induces APP cleavage. (A) Our data suggest that HSV-1 binding to the heparan sulfate proteoaminoglycans (HSPGs) expressed on neuronal plasma membrane induces $\mathrm{Ca}^{2}+$ signals triggering APP phosphorylation at Thr668 that, in turn, increases $\beta$ - and $\gamma$-secretase activity. As a result, there is an increased production of $A \beta$ that aggregates to form oligomers of various size. The C-terminal APP fragment called AICD, created by the cleavage of $\gamma$ secretase is phosphorylated at Thr668 and internalized in the nucleus where it may modulate gene transcription. (B) Western blots showing representative experiments performed with 4G8 antibody and anti pAPPThr668 on intracellular lysates of neuronal cells. Asterisks in the blots indicate bands that are modified by $18 \mathrm{~h}$ of HSV-1 infection (hours post infection, hpi) with respect to the mock-infected conditions. Double asterisk in the Western blot for 4G8 indicates the APP fragment F35, characteristic of HSV-1 infected cells. (C) Cartoon indicating the amino acid sequences targeted by the different antibodies we used for Western blot and immunofluorescence experiments: 4G8 recognizes all APP fragments containing the amino acid sequence 17-24 of $A \beta$, independently on its cleavage. Therefore, it reacts with APP "full-length", and with all APP fragments that contain A $17-24$ sequence; PAPPThr668 antibody reacts with all C-terminus APP fragments containing phosphorylated Thr668, including APP full-length; anti A 42 C-terminus specifically reacts with the $C$-terminal part of $A \beta 42$, and it does not recognize APP. Western blots in the panel $\mathbf{B}$ refer to previously published data (De Chiara etal., 2010). 

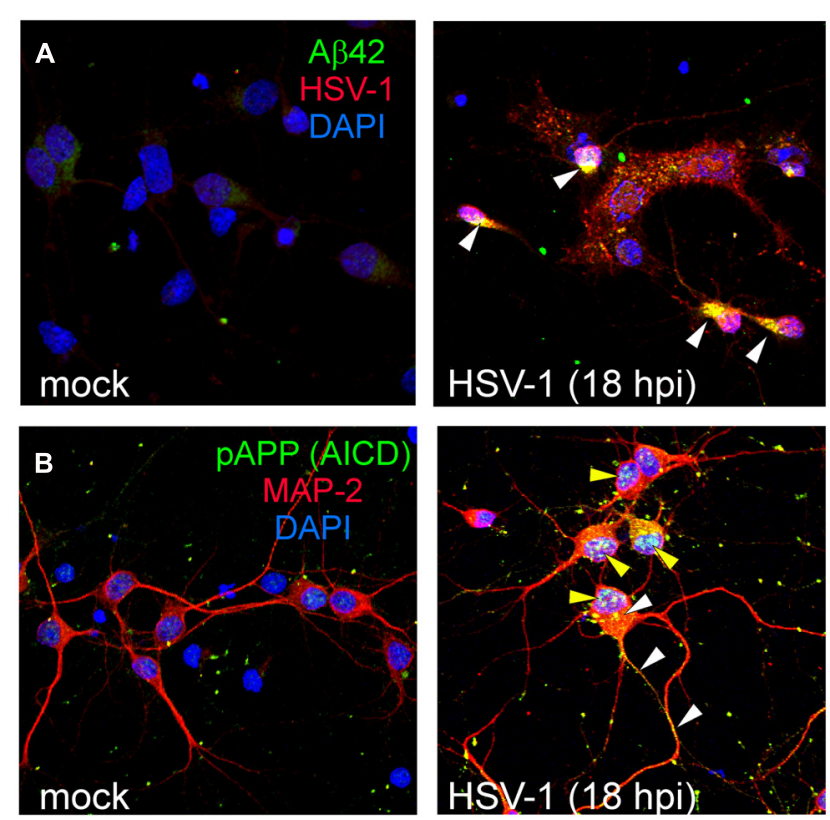

FIGURE 2 | HSV-1 infection induces intracellular accumulation of several APP fragments. Representative examples of mock and HSV-1-infected (18 hpi) rat cortical neurons immunostained for A $\beta 42$ C-terminus (green) and HSV-1 (red; A); pAPPThr668/AICD ${ }^{\text {Thr668 }}$ (green) and MAP-2 (red; B). Nuclei are stained in blue with DAPI. White arrowheads in the panel $\mathbf{A}$ (right) indicate intracellular accumulation of $A \beta 42$ in infected (HSV-1-positive) neurons. In the panel B (right), yellow arrowheads indicate nuclear accumulation of AICD ${ }^{\text {Thr668 }}$ in infected neurons (MAP-2-positive) whereas white arrowheads indicate staining for putative APP full-length phosphorylated at Thr668. Images in the panels A and $\mathbf{B}$ refer to previously published data (Piacentini et al., 2011).

(Lerchundi et al., 2011); activation of the arachidonic acid cascade, which is involved in AD-type neuropathological changes (Hill et al., 2009). With regard to the interaction between herpes simplex viruses and APP, it has been recently shown that HSV1 alters the distribution of cellular APP, and APP and HSV-1 capsid proteins physically interact to allow the migration of new viral particles inside infected cells by fast anterograde transport mechanisms (Cheng et al., 2011). This also suggests that HSV-1 affects APP dynamic and its intracellular distribution thus possibly causing alterations in its metabolism and processing.

\section{POSSIBLE HSV-1 RELATED THERAPEUTIC INTERVENTIONS}

Experimental evidence reviewed above allows us to hypothesize that, in the near future, treatments aimed at preventing and/or delaying AD might include antiviral agents and/or target HSV-1activated intracellular pathways. At the present, the main antiviral agent used for HSV-1 is Acyclovir. Acyclovir, that is the common name of acycloguanosine, targets infected cells and inhibits viral replication (Park et al., 1979). Wozniak et al. (2011) demonstrated that acyclovir reduced $\mathrm{A} \beta$ formation and Tau phosphorylation in vitro. This finding suggests that the appearance of molecular $\mathrm{AD}$ hallmarks depends on HSV-1 replication. Similarly, we observed that in rat cortical neurons, UV-inactivation of HSV-1 particles prevented $\mathrm{A} \beta 42$ formation and its intracellular accumulation, although the virus retained the ability to bind the neuronal membrane and trigger intracellular signaling leading to short-term APP phosphorylation (Piacentini et al., 2011). Itzhaki suggested that treatment with a variant of acyclovir, the valacyclovir, could be of great interest in treatment of HSV-1-induced neurodegeneration (Itzhaki and Wozniak, 2012). Indeed, valacyclovir displays greater bioavailability than acyclovir (5-fold to 10 -fold), it crosses the blood brain barrier and has no toxicity when used in patients with multiple sclerosis (Friedman et al., 2005). Interestingly, lysine supplementation has been suggested to have a role in preventing the development of AD by reducing HSV-1 replication (Rubey, 2010).

Among the proposed pharmacological treatments for $\mathrm{AD}$, the use of statins seems to be promising (Barone et al., 2013). It has been suggested that their beneficial effects may be related to their ability to modulate the entry of pathogens given that cholesterol synthesis inhibition blocks the entry, and limits neuronal spread, of HSV-1 (Hill et al., 2005).

Finally, some studies also suggested the use of GSK-3 $\beta$ inhibitors as possible candidates for $\mathrm{AD}$ treatment (King et al., 2014). Among them, lithium has been shown to have some beneficial effects on AD symptoms (see references in Forlenza et al., 2012; Nunes et al., 2013). Lithium has also been reported to inhibit HSV1 replication both in vitro and in vivo (Ziaie and Kefalides, 1989; Ziaie et al., 1994; Amsterdam et al., 1996), thus allowing to speculate that its beneficial effects might also depend on its antiviral activity.

\section{CONCLUSION}

Data reviewed here support the hypothesis that recurrent HSV-1 infection in the brain may have a critical role in $\mathrm{AD}$ pathogenesis by directly activating intracellular pathways leading to typical $\mathrm{AD}$ molecular hallmarks. Studies ongoing in our laboratory on in vivo models of recurrent mild brain HSV-1 infection will expectedly further support the causal relationship between HSV-1 reactivation in the CNS and $\mathrm{AD}$-like cognitive decline. Collectively, data discussed in this manuscript indicate that greater attention should be paid to infectious and, especially, viral agents among the environmental factors contributing to $\mathrm{AD}$ pathogenesis.

\section{ACKNOWLEDGMENTS}

This work was supported by grant from the Italian Ministry of Research (PRIN-2009PM9B33) to Claudio Grassi and Anna T. Palamara.

\section{REFERENCES}

Amsterdam, J. D., Maislin, G., and Hooper, M. B. (1996). Suppression of herpes simplex virus infections with oral lithium carbonate - a possible antiviral activity. Pharmacotherapy 16, 1070-1075.

Ando, Y., Kitayama, H., Kawaguchi, Y., and Koyanagi, Y. (2008). Primary target cells of herpes simplex virus type 1 in the hippocampus. Microbes Infect. 10, 1514-1523. doi: 10.1016/j.micinf.2008.09.005

Bading, H. (2013). Nuclear calcium signalling in the regulation of brain function. Nat. Rev. Neurosci. 14, 593-608. doi: 10.1038/nrn3531

Ball, M. J. (1982). Limbic predilection in Alzheimer dementia: is reactivated herpesvirus involved? Can. J. Neurol. Sci. 9, 303-306.

Barone, E., Di Domenico, F., and Butterfield, D. A. (2013). Statins more than cholesterol lowering agents in Alzheimer disease: their pleiotropic functions as potential therapeutic targets. Biochem. Pharmacol. 88, 605-616. doi: 10.1016/j.bcp.2013.10.030 
Bearer, E. L. (2012). HSV, axonal transport and Alzheimer's disease: in vitro and in vivo evidence for causal relationships. Future Virol. 7, 885-899. doi: $10.2217 /$ fvl.12.81

Beffert, U., Bertrand, P., Champagne, D., Gauthier, S., and Poirier, J. (1998). HSV-1 in brain and risk of Alzheimer's disease. Lancet 351, 1330-1331. doi: 10.1016/S0140-6736(05)79057-7

Blennow, K., Hampel, H., Weiner, M., and Zetterberg, H. (2010). Cerebrospinal fluid and plasma biomarkers in Alzheimer disease. Nat. Rev. Neurol. 6, 131-144. doi: 10.1038/nrneurol.2010.4

Bórquez, D. A., and González-Billault, C. (2012). The amyloid precursor protein intracellular domain-fe65 multiprotein complexes: a challenge to the amyloid hypothesis for Alzheimer's disease? Int. J. Alzheimers Dis. 2012, 353145. doi: $10.1155 / 2012 / 353145$

Burgos, J. S., Ramirez, C., Sastre, I., Bullido, M. J., and Valdivieso, F. (2002). Involvement of apolipoprotein $\mathrm{E}$ in the hematogenous route of herpes simplex virus type 1 to the central nervous system. J. Virol. 76, 12394-12398. doi: 10.1128/JVI.76.23.12394-12398.2002

Burgos, J. S., Ramirez, C., Sastre, I., Bullido, M. J., and Valdivieso, F. (2003). ApoE4 is more efficient than E3 in brain access by herpes simplex virus type 1. Neuroreport 14, 1825-1827. doi: 10.1097/00001756-200310060-00013

Burgos, J. S., Ramirez, C., Sastre, I., Alfaro, J. M., and Valdivieso, F. (2005). Herpes simplex virus type 1 infection via the bloodstream with apolipoprotein $\mathrm{E}$ dependence in the gonads is influenced by gender. J. Virol. 79, 1605-1612. doi: 10.1128/JVI.79.3.1605-1612.2005

Burgos, J. S., Ramirez, C., Guzman-Sanchez, F., Alfaro, J. M., Sastre, I., and Valdivieso F. (2006a). Hematogenous vertical transmission of herpes simplex virus type 1 in mice. J. Virol. 80, 2823-2831. doi: 10.1128/JVI.80.6.2823-2831.2006

Burgos, J. S., Ramirez, C., Sastre, I., and Valdivieso, F. (2006b). Effect of apolipoprotein E on the cerebral load of latent herpes simplex virus type 1 DNA. J. Virol. 80, 5383-5387. doi: 10.1128/JVI.00006-06

Caparros-Lefebvre, D., Girard-Buttaz, I., Reboul, S., Lebert, F., Cabaret, M., Verier, A., et al. (1996). Cognitive and psychiatric impairment in herpes simplex virus encephalitis suggest involvement of the amygdalo-frontal pathways. J. Neurol. 243, 248-256. doi: 10.1007/BF00868522

Carter, C. J. (2008). Interactions between the products of the Herpes simplex genome and Alzheimer's disease susceptibility genes: relevance to pathological-signalling cascades. Neurochem. Int. 52, 920-934. doi: 10.1016/j.neuint.2007.11.003

Chakroborty, S., Briggs, C., Miller, M. B., Goussakov, I., Schneider, C., Kim, J., et al (2012). Stabilizing ER $\mathrm{Ca}^{2+}$ channel function as an early preventative strategy for Alzheimer's disease. PLoS ONE 7:e52056. doi: 10.1371/journal.pone.0052056

Chang, K. A., Kim, H. S., Ha, T. Y., Ha, J. W., Shin, K. Y., Jeong, Y. H., et al. (2006). Phosphorylation of amyloid precursor protein (APP) at Thr668 regulates the nuclear translocation of the APP intracellular domain and induces neurodegeneration. Mol. Cell. Biol. 26, 4327-4338. doi: 10.1128/MCB.02393-05

Cheng, S. B., Ferland, P., Webster, P., and Bearer, E. L. (2011). Herpes simplex virus dances with amyloid precursor protein while exiting the cell. PLOS ONE 6:e17966. doi: 10.1371/journal.pone.0017966

Choy, R. W., Cheng, Z., and Schekman, R. (2012). Amyloid precursor protein (APP) traffics from the cell surface via endosomes for amyloid $\beta(A \beta)$ production in the trans-Golgi network. Proc. Natl. Acad. Sci. U.S.A. 109, E2077-E2082. doi: 10.1073/pnas.1208635109

Cook, D. G., Forman, M. S., Sung, J. C., Leight, S., Kolson, D. L., Iwatsubo, T., et al. (1997). Alzheimer's $A \beta(1-42)$ is generated in the endoplasmic reticulum/intermediate compartment of NT2N cells. Nat. Med. 3, 1021-1023.

Cribbs, D. H., Azizeh, B. Y., Cotman, C. W., and LaFerla, F. M. (2000). Fibril formation and neurotoxicity by a herpes simplex virus glycoprotein B fragment with homology to the Alzheimer's A $\beta$ peptide. Biochemistry 39, 5988-5994.

Damasio, A. R., and Van Hoesen, G. W. (1985). The limbic system and the localisation of herpes simplex encephalitis. J. Neurol. Neurosurg. Psychiatry 48, 297-301. doi: 10.1136/jnnp.48.4.297

Deatly, A. M., Spivack, J. G., Lavi, E., O’Boyle, D. R. II, and Fraser, N. W. (1988). Latent herpes simplex virus type 1 transcripts in peripheral and central nervous system tissues of mice map to similar regions of the viral genome. J. Virol. 62, 749-756.

De Chiara, G., Marcocci, M. E., Civitelli, L., Argnani, R., Piacentini, R., Ripoli, C., et al. (2010). APP processing induced by herpes simplex virus type 1 (HSV1) yields several APP fragments in human and rat neuronal cells. PLoS ONE 5:e13989. doi: 10.1371/journal.pone.0013989
Dobson, C. B., Wozniak, M. A., and Itzhaki, R. F. (2003). Do infectious agents play a role in dementia? Trends Microbiol. 11, 312-317. doi: 10.1016/S0966$842 \mathrm{X}(03) 00146-\mathrm{X}$

Féart, C., Helmer, C., Fleury, H., Béjot, Y., Ritchie, K., Amouyel, P., et al. (2011). Association between IgM anti-herpes simplex virus and plasma amyloid- $\beta$ levels. PLoS ONE 6:e29480. doi: 10.1371/journal.pone.0029480

Fiorelli, T., Kirouac, L., and Padmanabhan, J. (2013). Altered processing of amyloid precursor protein in cells undergoing apoptosis. PLoS ONE 8:e57979. doi: 10.1371/journal.pone.0057979

Forlenza, O. V., de Paula, V. J., Machado-Vieira, R., Diniz, B. S., and Gattaz, W. F. (2012). Does lithium prevent Alzheimer's disease? Drugs Aging 29, 335-342. doi: 10.2165/11599180-000000000-00000

Friedman, J. E., Zabriskie, J. B., Plank, C., Ablashi, D., Whitman, J., Shahan, B., et al. (2005). A randomized clinical trial of valacyclovir in multiple sclerosis. Mult. Scler. 11, 286-295. doi: 10.1191/1352458505ms1185oa

Gervais, F. G., Xu, D., Robertson, G. S., Vaillancourt, J. P., Zhu, Y., Huang, J., et al. (1999). Involvement of caspases in proteolytic cleavage of Alzheimer's amyloid- $\beta$ precursor protein and amyloidogenic A $\beta$ peptide formation. Cell 97, 395-406. doi: 10.1016/S0092-8674(00)80748-5

Green, K. N. (2009). Calcium in the initiation, progression and as an effector of Alzheimer's disease pathology. J. Cell. Mol. Med. 13, 2787-2799. doi: 10.1111/j.1582-4934.2009.00861.x

Hashimoto, T., Serrano-Pozo, A., Hori, Y., Adams, K. W., Takeda, S., Banerji, A. O., et al. (2012). Apolipoprotein E, especially apolipoprotein E4, increases the oligomerization of amyloid $\beta$ peptide. J. Neurosci. 32, 15181-15192. doi: 10.1523/JNEUROSCI.1542-12.2012

Hill, J. M., Steiner, I., Matthews, K. E., Trahan, S. G., Foster, T. P., and Ball, M. J. (2005). Statins lower the risk of developing Alzheimer's disease by limiting lipid raft endocytosis and decreasing the neuronal spread of Herpes simplex virus type 1. Med. Hypotheses 64, 53-58. doi: 10.1016/j.mehy.2003. 12.058

Hill, J. M., Zhao, Y., Clement, C., Neumann, D. M., and Lukiw, W. J. (2009). HSV-1 infection of human brain cells induces miRNA-146a and Alzheimer-type inflammatory signaling. Neuroreport 20, 1500-1505. doi: 10.1097/WNR.0b013e3283329c05

Holtzman, D. M., Bales, K. R., Tenkova, T., Fagan, A. M., Parsadanian, M., Sartorius, L. J., et al. (2000). Apolipoprotein E isoform-dependent amyloid deposition and neuritic degeneration in a mouse model of Alzheimer's disease. Proc. Natl. Acad. Sci. U.S.A. 97, 2892-2897. doi: 10.1073/pnas.050004797

Holtzman, D. M., Herz, J., and Bu, G. (2012). Apolipoprotein E and apolipoprotein E receptors: normal biology and roles in Alzheimer disease. Cold Spring Harb. Perspect. Med. 2, a006312. doi: 10.1101/cshperspect.a006312

Imtiaz, B., Tolppanen, A. M., Kivipelto, M., and Soininen, H. (2014). Future directions in Alzheimer's disease from risk factors to prevention. Biochem. Pharmacol. 88, 661-670. doi: 10.1016/j.bcp.2014.01.003

Itzhaki, R. F., and Lin, W. R. (1998). Herpes simplex virus type I in brain and the type 4 allele of the apolipoprotein E gene are a combined risk factor for Alzheimer's disease. Biochem. Soc. Trans. 26, 273-277.

Itzhaki, R. F., Lin, W. R., Shang, D., Wilcock, G. K., Faragher, B., and Jamieson, G. A. (1997). Herpes simplex virus type 1 in brain and risk of Alzheimer's disease. Lancet 349, 241-244. doi: 10.1016/S0140-6736(96)10149-5

Itzhaki, R., and Wozniak, M. (2008). Susceptibility to herpes simplex labialis conferred by the gene encoding apolipoprotein E. J. Infect. Dis. 198, 624-625; author reply 625-626. doi: 10.1086/590213

Itzhaki, R. F., Wozniak, M., Dobson, C., and Lin, W. R. (1998). ApoE-viral interactions. Nat. Med. 4, 1344. doi: 10.1038/3908

Itzhaki, R. F., and Wozniak, M. A. (2012). Could antivirals be used to treat Alzheimer's disease? Future Microbiol. 7, 307-309. doi: 10.2217/fmb.12.10

Jamieson, G. A., Maitland, N. J., Wilcock, G. K., Yates, C. M., and Itzhaki, R. F. (1992). Herpes simplex virus type 1 DNA is present in specific regions of brain from aged people with and without senile dementia of the Alzheimer type. J. Pathol. 167, 365-368. doi: 10.1002/path.1711670403

Kastrukoff, L., Hamada, T., Schumacher, U., Long, C., Doherty, P. C., and Koprowski, H. (1982). Central nervous system infection and immune response in mice inoculated into the lip with herpes simplex virus type 1. J. Neuroimmunol. 2, 295-305. doi: 10.1016/0165-5728(82)90062-5

Kim, J., Basak, J. M., and Holtzman, D. M. (2009). The role of apolipoprotein E in Alzheimer's disease. Neuron 63, 287-303. doi: 10.1016/j.neuron.2009.06.026 
King, M. K., Pardo, M., Cheng, Y., Downey, K., Jope, R. S., and Beurel, E. (2014). Glycogen synthase kinase-3 inhibitors: rescuers of cognitive impairments. Pharmacol. Ther. 141, 1-12. doi: 10.1016/j.pharmthera.2013.07.010

Kitazawa, M., Yamasaki, T. R., and LaFerla, F. M. (2004). Microglia as a potential bridge between the amyloid $\beta$-peptide and tau. Ann. N. Y. Acad. Sci. 1035, 85-103. doi: 10.1196/annals.1332.006

Kobayashi, N., Nagata, T., Shinagawa, S., Oka, N., Shimada, K., Shimizu, A., et al. (2013). Increase in the IgG avidity index due to herpes simplex virus type 1 reactivation and its relationship with cognitive function in amnestic mild cognitive impairment and Alzheimer's disease. Biochem. Biophys. Res. Commun. 430, 907-911. doi: 10.1016/j.bbrc.2012. 12.054

Kosik, K. S., Joachim, C. L., and Selkoe, D. J. (1986). Microtubule-associated protein tau $(\tau)$ is a major antigenic component of paired helical filaments in Alzheimer disease. Proc. Natl. Acad. Sci. U.S.A. 83, 4044-4048. doi: 10.1073/pnas.83. 11.4044

Lambert, J. C., Schraen-Maschke, S., Richard, F., Fievet, N., Rouaud, O., Berr, C., etal. (2009). Association of plasma amyloid $\beta$ with risk of dementia: the prospective Three-City Study. Neurology 73, 847-853. doi: 10.1212/WNL.0b013e3181b78448

Lee, M. S., Kao, S. C., Lemere, C. A., Xia, W., Tseng, H. C., Zhou, Y., et al. (2003). APP processing is regulated by cytoplasmic phosphorylation. J. Cell Biol. 163, 83-95. doi: $10.1083 /$ jcb. 200301115

Lerchundi, R., Neira, R., Valdivia, S., Vio, K., Concha, M. I., Zambrano, A., et al. (2011). Tau cleavage at D421 by caspase- 3 is induced in neurons and astrocytes infected with herpes simplex virus type 1. J. Alzheimers Dis. 23, 513-520. doi: 10.3233/JAD-2010-101386

Letenneur, L., Pérès, K., Fleury, H., Garrigue, I., Barberger-Gateau, P., Helmer C., et al. (2008). Seropositivity to herpes simplex virus antibodies and risk of Alzheimer's disease: a population-based cohort study. PLoS ONE 3:e3637. doi: 10.1371/journal.pone.0003637

Lewandowski, G., Zimmerman, M. N., Denk, L. L., Porter, D. D., and Prince, G. A. (2002). Herpes simplex type 1 infects and establishes latency in the brain and trigeminal ganglia during primary infection of the lip in cotton rats and mice. Arch. Virol. 147, 167-179. doi: 10.1007/s705-002 8309-9

Licastro, F., Carbone, I., Ianni, M., and Porcellini, E. (2011). Gene signature in Alzheimer's disease and environmental factors: the virus chronicle. J. Alzheimers Dis. 27, 809-817. doi: 10.3233/JAD-2011-110755

Lu, D. C., Soriano, S., Bredesen, D. E., and Koo, E. H. (2003). Caspase cleavage of the amyloid precursor protein modulates amyloid $\beta$-protein toxicity. J. Neurochem. 87, 733-741. doi: 10.1046/j.1471-4159.2003.02059.x

Maiti, P., Piacentini, R., Ripoli, C., Grassi, C., and Bitan, G. (2011). Surprising toxicity and assembly behaviour of amyloid $\beta$-protein oxidized to sulfone. Biochem J. 433, 323-332. doi: 10.1042/BJ20101391

Mancuso, R., Baglio, F., Cabinio, M., Calabrese, E., Hernis, A., Nemni, R., et al (2014). Titers of herpes simplex virus type 1 antibodies positively correlate with grey matter volumes in Alzheimer's disease. J. Alzheimers Dis. 38, 741-745. doi 10.3233/JAD-130977

Martin, C., Aguila, B., Araya, P., Vio, K., Valdivia, S., Zambrano, A., et al. (2013). Inflammatory and neurodegeneration markers during asymptomatic HSV-1 reactivation. J. Alzheimers Dis. 39, 849-859. doi: 10.3233/JAD131706

Mattson, M. P., Barger, S. W., Cheng, B., Lieberburg, I., Smith-Swintosky, V. L. and Rydel, R. E. (1993). $\beta$-Amyloid precursor protein metabolites and loss of neuronal $\mathrm{Ca}^{2+}$ homeostasis in Alzheimer's disease. Trends Neurosci. 16, 409-414. doi: 10.1016/0166-2236(93)90009-B

Mattson, M. P., and Chan, S. L. (2003). Calcium orchestrates apoptosis. Nat. Cell Biol. 5, 1041-1043. doi: 10.1038/ncb1203-1041

Mohamed, A., and Posse de Chaves, E. (2011). A $\beta$ internalization by neurons and glia. Int. J. Alzheimers Dis. 2011, 127984. doi: 10.4061/2011/127984

Müller, W., Meske, V., Berlin, K., Scharnagl, H., März, W., and Ohm, T. G. (1998). Apolipoprotein $\mathrm{E}$ isoforms increase intracellular $\mathrm{Ca}^{2+}$ differentially through a omega-agatoxin IVa-sensitive $\mathrm{Ca}^{2+}$-channel. Brain Pathol. 8, 641-653. doi: 10.1111/j.1750-3639.1998.tb00190.x

Mucke, L., and Selkoe, D. J. (2012). Neurotoxicity of amyloid $\beta$-protein: synaptic and network dysfunction. Cold Spring Harb. Perspect Med. 2, a006338. doi: $10.1101 /$ cshperspect.a006338
Nguyen, T. V., Galvan, V., Huang, W., Banwait, S., Tang, H., Zhang, J., et al. (2008). Signal transduction in Alzheimer disease: p21-activated kinase signaling requires C-terminal cleavage of APP at Asp664. J. Neurochem. 104, 1065-1080. doi: 10.1111/j.1471-4159.2007.05031.x

Nunan, J., and Small, D. H. (2000). Regulation of APP cleavage by $\alpha-, \beta$ - and $\gamma$-secretases. FEBS Lett. 483, 6-10. doi: 10.1016/S0014-5793(00)02076-7

Nunes, M. A., Viel, T. A., and Buck, H. S. (2013). Microdose lithium treatment stabilized cognitive impairment in patients with Alzheimer's disease. Curr. Alzheimer Res. 10, 104-107. doi: 10.2174/156720513804871354

Octave, J. N., Pierrot, N., Ferao Santos, S., Nalivaeva, N. N., and Turner, A. J. (2013). From synaptic spines to nuclear signaling: nuclear and synaptic actions of the amyloid precursor protein. J. Neurochem. 126, 183-190. doi: 10.1111/jnc. 12239

Park, N. H., Pavan-Langston, D., and McLean, S. L. (1979). Acylovir in oral and ganglionic herpes simplex virus infections. J. Infect. Dis. 140, 802-806. doi: 10.1093/infdis/140.5.802

Pellegrini, L., Passer, B. J., Tabaton, M., Ganjei, J. K., and D’Adamio, L. (1999). Alternative, non-secretase processing of Alzheimer's $\beta$-amyloid precursor protein during apoptosis by caspase-6 and -8. J. Biol. Chem. 274, 21011-21016. doi: 10.1074/jbc. 274.30 .21011

Peter, J. B., and Sevall, J. S. (2001). Review of 3200 serially received CSF samples submitted for type-specific HSV detection by PCR in the reference laboratory setting. Mol. Cell. Probes 15, 177-182. doi: 10.1006/mcpr.2001.0356

Piacentini, R., Civitelli, L., Ripoli, C., Marcocci, M. E., De Chiara, G., Garaci, E., et al. (2011). HSV-1 promotes $\mathrm{Ca}^{2+}$-mediated APP phosphorylation and A $\beta$ accumulation in rat cortical neurons. Neurobiol. Aging 32, 2323.e13-2323.e26.

Piacentini, R., Gangitano, C., Ceccariglia, S., Del Fà, A., Azzena, G. B., Michetti, F., et al. (2008a). Dysregulation of intracellular calcium homeostasis is responsible for neuronal death in an experimental model of selective hippocampal degeneration induced by trimethyltin. J. Neurochem. 105, 2109-2121. doi: 10.1111/j.1471-4159.2008.05297.x

Piacentini, R., Ripoli, C., Leone, L., Misiti, F., Clementi, M. E., D’Ascenzo, M., et al. (2008b). Role of methionine 35 in the intracellular $\mathrm{Ca}^{2+}$ homeostasis dysregulation and $\mathrm{Ca}^{2+}$-dependent apoptosis induced by amyloid $\beta$-peptide in human neuroblastoma IMR32 cells. J. Neurochem. 107, 1070-1082.

Pierrot, N., Santos, S. F., Feyt, C., Morel, M., Brion, J. P., and Octave, J. N. (2006). Calcium-mediated transient phosphorylation of tau and amyloid precursor protein followed by intraneuronal amyloid- $\beta$ accumulation. J. Biol. Chem. 281, 39907-39914. doi: 10.1074/jbc.M606015200

Plentz, A., Jilg, W., Kochanowski, B., Ibach, B., and Knöll, A. (2008). Detection of herpesvirus DNA in cerebrospinal fluid and correlation with clinical symptoms. Infection 36, 158-162. doi: 10.1007/s15010-007-6354-y

Porcellini, E., Carbone, I., Ianni, M., and Licastro, F. (2010). Alzheimer's disease gene signature says: beware of brain viral infections. Immun. Ageing 7, 16. doi: $10.1186 / 1742-4933-7-16$

Puzzo, D., Privitera, L., Fa', M., Staniszewski, A., Hashimoto, G., Aziz, F., et al. (2011). Endogenous amyloid- $\beta$ is necessary for hippocampal synaptic plasticity and memory. Ann. Neurol. 69, 819-830. doi: 10.1002/ana.22313

Puzzo, D., Privitera, L., Leznik, E., Fà, M., Staniszewski, A., Palmeri, A., et al. (2008). Picomolar amyloid- $\beta$ positively modulates synaptic plasticity and memory in hippocampus. J. Neurosci. 28, 14537-14545. doi: 10.1523/JNEUROSCI.269208.2008

Ripoli, C., Piacentini, R., Riccardi, E., Leone, L., Li Puma, D. D., Bitan, G., et al. (2013). Effects of different amyloid $\beta$-protein analogues on synaptic function. Neurobiol. Aging 34, 1032-1044. doi: 10.1016/j.neurobiolaging.2012.06.027

Rubey, R. N. (2010). Could lysine supplementation prevent Alzheimer's dementia? A novel hypothesis. Neuropsychiatr. Dis. Treat. 6, 707-710. doi: 10.2147/NDT.S14338

Schupf, N., Tang, M. X., Fukuyama, H., Manly, J., Andrews, H., Mehta, P., et al. (2008). Peripheral A $\beta$ subspecies as risk biomarkers of Alzheimer's disease. Proc. Natl. Acad. Sci. U.S.A. 105, 14052-14057. doi: 10.1073/pnas.0805902105

Shipley, S. J., Parkin, E. T., Itzhaki, R. F., and Dobson, C. B. (2005). Herpes simplex virus interferes with amyloid precursor protein processing. BMC Microbiol. 5:48. doi: 10.1186/1471-2180-5-48

Tampellini, D., Magrané, J., Takahashi, R. H., Li, F., Lin, M. T., Almeida, C. G., et al. (2007). Internalized antibodies to the A $\beta$ domain of APP reduce neuronal $\mathrm{A} \beta$ and protect against synaptic alterations. J. Biol. Chem. 282, 18895-18906. doi: 10.1074/jbc.M700373200 
Taylor, S. W., Lee, D. H., and Jackson, A. C. (2007). Herpes simplex encephalitis presenting with exclusively frontal lobe involvement. J. Neurovirol. 13, 477-481. doi: 10.1080/13550280701491131

Vassar, R., Bennett, B. D., Babu-Khan, S., Kahn, S., Mendiaz, E. A., Denis, P., et al. (1999). $\beta$-secretase cleavage of Alzheimer's amyloid precursor protein by the transmembrane aspartic protease BACE. Science 286, 735-741. doi: $10.1126 /$ science.286.5440.735

Verghese, P. B., Castellano, J. M., Garai, K., Wang, Y., Jiang, H., Shah, A., et al. (2013). ApoE influences amyloid- $\beta$ (A $\beta)$ clearance despite minimal apoE/A $\beta$ association in physiological conditions. Proc. Natl. Acad. Sci. U.S.A. 110, E1807-E1816. doi: $10.1073 /$ pnas. 1220484110

Vetrivel, K. S., and Thinakaran, G. (2006). Amyloidogenic processing of $\beta$-amyloid precursor protein in intracellular compartments. Neurology 66, S69-S73. doi: 10.1212/01.wnl.0000192107.17175.39

Whitwell, J. L., Dickson, D. W., Murray, M. E., Weigand, S. D., Tosakulwong, N., Senjem, M. L., et al. (2012). Neuroimaging correlates of pathologically defined subtypes of Alzheimer's disease: a casecontrol study. Lancet Neurol. 11, 868-877. doi: 10.1016/S1474-4422(12) 70200-4

Wozniak, M. A., Mee, A. P., and Itzhaki, R. F. (2009a). Herpes simplex virus type1 DNA is located within Alzheimer's disease amyloid plaques. J. Pathol. 217, 131138. doi: 10.1002/path.2449

Wozniak, M. A., Frost, A. L., and Itzhaki, R. F. (2009b). Alzheimer's disease specific tau phosphorylation is induced by herpes simplex virus type 1. J. Alzheimers Dis. 16, 341-350. doi: 10.3233/JAD-2009-0963

Wozniak, M. A., Frost, A. L., Preston, C. M., and Itzhaki, R. F. (2011). Antivirals reduce the formation of key Alzheimer's disease molecules in cell cultures acutely infected with herpes simplex virus type 1. PLOS ONE 6:e25152. doi: 10.1371/journal.pone.0025152

Wozniak, M. A., Itzhaki, R. F., Shipley, S. J., and Dobson, C. B. (2007). Herpes simplex virus infection causes cellular $\beta$-amyloid accumulation and secretase upregulation. Neurosci. Lett. 429, 95-100. doi: 10.1016/j.neulet.2007. 09.077

Wu, H. M., Huang, C. C., Chen, S. H., Liang, Y. C., Tsai, J. J., Hsieh, C. L., et al. (2003). Herpes simplex virus type 1 inoculation enhances hippocampal excitability and seizure susceptibility in mice. Eur. J. Neurosci. 18, 3294-3304. doi: 10.1111/j.14609568.2003.03075.x

Zambrano, A., Solis, L., Salvadores, N., Cortés, M., Lerchundi, R., and Otth, C. (2008). Neuronal cytoskeletal dynamic modification and neurodegeneration induced by infection with herpes simplex virus type 1. J. Alzheimers Dis. 14, 259-269.

Zhang, Y. W., Thompson, R., Zhang, H., and Xu, H. (2011). APP processing in Alzheimer's disease. Mol. Brain 4, 3. doi: 10.1186/1756-6606-4-3

Zheng, H., and Koo, E. H. (2006). The amyloid precursor protein: beyond amyloid. Mol. Neurodegener. 1, 5. doi: 10.1186/1750-1326-1-5

Ziaie, Z., Brinker, J. M., and Kefalides, N. A. (1994). Lithium chloride suppresses the synthesis of messenger RNA for infected cell protein- 4 and viral deoxyribonucleic acid polymerase in herpes simplex virus- 1 infected endothelial cells. Lab. Invest. 70, 29-38.

Ziaie, Z., and Kefalides, N. A. (1989). Lithium chloride restores host protein synthesis in herpes simplex virus-infected endothelial cells. Biochem. Biophys. Res. Commun. 160, 1073-1078. doi: 10.1016/S0006-291X(89)80112-3

Conflict of Interest Statement: The authors declare that the research was conducted in the absence of any commercial or financial relationships that could be construed as a potential conflict of interest.

Received: 28 February 2014; accepted: 16 April 2014; published online: 07 May 2014. Citation: Piacentini R, De Chiara G, Li Puma DD, Ripoli C, Marcocci ME, Garaci E, Palamara AT and Grassi C (2014) HSV-1 and Alzheimer's disease: more than a hypothesis. Front. Pharmacol. 5:97. doi: 10.3389/fphar.2014.00097

This article was submitted to Experimental Pharmacology and Drug Discovery, a section of the journal Frontiers in Pharmacology.

Copyright (c) 2014 Piacentini, De Chiara, Li Puma, Ripoli, Marcocci, Garaci, Palamara and Grassi. This is an open-access article distributed under the terms of the Creative Commons Attribution License (CC BY). The use, distribution or reproduction in other forums is permitted, provided the original author(s) or licensor are credited and that the original publication in this journal is cited, in accordance with accepted academic practice. No use, distribution or reproduction is permitted which does not comply with these terms. 